\title{
Development of a Technology and Digital Transformation Adoption Framework of the Postal Industry in Southern Africa: From Critical Literature Review to a Theoretical Framework
}

\author{
Kgabo Mokgohloa*, Grace Kanakana-Katumba, Rendani Maladzhi \\ Department of Mechanical and Industrial Engineering, University of South Africa, Johannesburg, 0002, South Africa
}

\author{
A R T I C L E IN F O \\ Article history: \\ Received: 30 August, 2020 \\ Accepted: 23 November, 2020 \\ Online: 14 December, 2020
}

Keywords:

Technology adoption

Systems approach

Digital transformation

\begin{abstract}
A B S T R A C T
The pressing and most urgent challenge for most of the Posts in Southern Africa is to transit from its historical reputation of being a snail-paced, inefficient, loss-making and ineffective service provider to an agile, innovative, solution-driven and highly competitive service provider that strive for excellence. In this context, adoption, and diffusion of technology and digital transformation by Posts should deliver the necessary traction to steer the digital transformation journey of the postal industry in Southern Africa with the necessary velocity while cognizant and mindful of the appropriateness of the technology in the African context in the light of a VUCA (Volatile, Uncertain, Complex and Ambiguous) world. The traditional technology adoption models are characterized by "linearity" which is the opposite of a dynamic setting characterized by "causality" which is the fundamental principle of a system thinking approach. The multi-stakeholders in the postal sector with often competing interests renders a linear approach defunct and requires a system approach to digital transformation and technology adoption. The conceptual framework developed from the critical review of literature offers considerable leverage to postal sector in developing countries and to Southern Africa in particular. The proposed conceptual framework integrates dimensions such as Postal Industry 4.0 Envisioning, Strategy, Institutional factors, Organizational factors, Individual factors, Industry 4.0 environment and outcomes.
\end{abstract}

\section{Introduction}

This paper is an extension of "Postal Development: Literature Review into Adoption Models" presented at IEEM 2019 Conference in Macau by authors in [1]. The rise of digitalization powered by a digital revolution of the 21 st century ushered by the Fourth Industrial Revolution and personified by Industry 4.0, has prompted the postal sector across the world to expand their services well beyond the original service of postal operators (POs) which was delivery of physical mail in the form of letters and post cards.

In [2], the authors propose that although there are Posts in different nations that are struggling to keep afloat due to economic and political turbulence there are other Posts that are trailblazers in postal digital transformation which is underpinned by digital innovation which leads to digital disruption. It comes as no surprise that Swiss Post, The Netherland Post, Deutsche Post, La Poste, and Japan Post are trailblazers in digital innovation.

*Corresponding Author: Kgabo Mokgohloa,mokgok@unisa.ac.za
In [3], the authors postulates that societal anatomy is rapidly changing, and that the digital age shepherded changes in consumption patterns which has resulted in the evolution of the customer of the future with unique needs and expectations that industries should meet. A systems (holistic) approach is required to comprehend a new world that is driven by volatility, uncertainty, complexity, and ambiguity (VUCA). VUCA world is categorised by the traits of volatility, uncertainty, complexity and ambiguity [4]. In [5], the authors argue that Volatility, Uncertainty, Complexity and Ambiguity (VUCA) explains the competitive ecosystem of the digital economy in which corporations ought to acclimate business process to match up briskly shifting and more complex dynamic settings.

In [6], the authors propose that in the current Volatile, Uncertain, Complex and Ambiguous (VUCA) world, organizations and employees are faced with a plethora of challenges that overly dynamic and totally different from the challenges of the past. In [6], the authors further argue that there are several of drivers that propel these changes, and that 
technology, accessibility to information, a fast shifting global economy, the establishment of a global consumer society and a very insistent customer with unique and diverse requirements are only some influences that have shaped an extremely complex and ambiguous world.

In [7], the authors advance that organizational and societal systems in the digital era encompass characteristics of volatility, uncertainty, complexity, and ambiguity; and as a result a systems approach to digital transformation and technology adoption is a key success factor for Posts in Southern Africa.

\subsection{Problem statement}

The crises that has befell on the Designated Postal Operators (DPOs) in Southern Africa has precipitated the near collapse of the postal logistics sector due poor performance on the four performance indicators of the 2IPD and consequently losses except for a few Designated Postal Operators making a profit, this is characterized by the scores respective Post in Southern Africa obtained on the 2IPD.

The underperformance by SADC DPOs is fuelled by a plethora of dynamics including inflexible or rather outdated business models that are not adapting to the technological changes that are disrupting current business models immensely, the archaic business models cannot compete in the 21st century and this result in majority of Postal Operators in Southern Africa posting losses year in year out. The unsustainability of the DPOs leave the State in respective countries with no option but to bail out these institutions. This performance is contrary to the first-tier countries who occupy pole positions on the integrated index on postal development (2IDP).

\subsection{Research question}

Can a technology and digital adoption framework in the context of postal industry 4.0 be developed for Posts in Southern Africa?

\subsection{Concluding remarks to introduction}

The paper is divided into (a) Introduction which introduces the phenomenon under study as well as articulating the problem statement and the research question which guided the research study. (b) Literature review which delved into the postal landscape, articulation of the Integrated Index on Postal Development (2IDP) which is a global measure of performance of the postal sector globally, and with specific reference to the top 5 performers on the 2IDP and digital readiness index. The literature review further delved into the phenomenon of industry 4.0, technology adoption, digital transformation, reductionist vs systems approach and capability maturity models. The report then detailed the research methods adopted, the discussion and findings that included the development of the theoretical framework, deductions and upcoming research concludes the study.

\section{Literature review}

\subsection{The Postal landscape}

In [2], the authors articulates an international view point of the Postal Industry, accentuating that the postal network encompasses a worldwide grid of over 677000 retail offices, 5.3 million members and substantial infrastructure comprising 192 nations.

In [8], the authors hypothesizes that imperfect internet connectivity, inadequate investment and/or recapitalization of the network infrastructure, deprived value of service, restricted interoperability and connectivity among the systems of value chain participants, as well as uncertainty in postal industry characterisation in southern Africa are the foremost motives for the snail-paced advancement.

In [9], the authors argues that the regional scenery of the postal industry in southern Africa encompass 50 mail centres and a distribution infrastructure of 16,064.394 deliverance points. Of these, South Africa has a lion share of 26 mail centres and 14, 106.896 delivery points. The postal industry in Southern Africa comprise of fourteen designated postal operators in South Africa, Botswana, Zambia, Eswatini, Seychelles, Democratic Republic of Congo, Malawi, Comoros, Madagascar, Mauritius, Tanzania, Lesotho, Mozambique, and Angola.

\subsection{The Integrated Index on Postal Development}

In [3], the authors note that most Posts are performing disappointingly on the Integrated Index for Postal Development (2IPD). In [3], the authors further proposes that measuring the multiple facets of postal development is no insignificant task, and hypothesize that in order to surmount this difficulty; the Universal Postal Union (UPU) has been tapping on abundance of postal big data to appraise the performance of Posts globally. One of the most important sequels of these endeavours was the development of the Integrated Index for Postal Development commonly known as the 2IPD. In [10], the author argues that 2IPD gauges the performance of Posts in the four vital aspects of postal advancement which are known as the 4Rs (reliability, reach, relevance and resilience).

In [11], the authors outlines the four aspects of postal advancement (development) as follows: (a) Reliability is a fusion of excellence of service delivery, including certainty across all categories of postal delivery service; it eventually gauges the level of postal operational efficiency (b) Reach is fusion of worldwide postal connectedness at intercontinental level across all categories of international postal delivery services, it ultimately gauges the level of globalization of the postal services (c) Relevance encompass the strength of demand for the full range of postal services in each postal section; it eventually gauges the level of attractiveness of the postal market (d) Resilience encompass ability to innovate, deliver wide-ranging postal services and assimilate sustainable development targets in postal business models; it ultimately gauges the level of adaptableness of postal business models.

In [3], the authors advances that a total of 172 countries were analysed for the development of the 2019 global ranking (based on complete data for 2018). Table 1 depicts the top 5 countries in alphabetical order with their corresponding scores on the 2IDP and are as follows: France, Germany, Japan, Netherlands, and Switzerland. In [12], the authors postulates that these top 5 DPO's are performing outstandingly on the 2IDP because they have steadily build dependable, well-connected, appropriate and agile postal services. The report further highlights that other DPOs 
especially in developing countries are underperforming relative to the 2IDP indicators.

Table.1: Top 5 Designated Postal Operators performance on Integrated Index for Postal Development, adapted from [12]

\begin{tabular}{|l|c|c|}
\hline Country & 2IPD Score 2018 & 2IPD Score 2019 \\
\hline France & 83.3 & 86.86 \\
\hline Germany & 91.3 & 90.79 \\
\hline Japan & 91.6 & 87.19 \\
\hline Netherlands & 93.7 & 93.67 \\
\hline Switzerland & 100 & 100 \\
\hline
\end{tabular}

The analysis of performance on the 2IPD points to Posts in developing countries (Southern Africa included) as laggards' when compared to the top performing DPOs on the 2IPD. Table 2 lists the SADC (Southern African Development Community) Designated Postal Operators with their corresponding 2IPD scores.

Table.2: Southern African Development Community Designated Postal Operators performance on Integrated Index for Postal Development, adapted from [12]

\begin{tabular}{|l|c|c|}
\hline \multicolumn{1}{|c|}{ Country } & $\begin{array}{c}\text { 2IPD } \\
\text { Scores } 2018\end{array}$ & 2IPD Scores 2019 \\
\hline Angola & 21.22 & 30.54 \\
\hline Botswana & 23.72 & 21.00 \\
\hline Comoros & 11.29 & 11.76 \\
\hline $\begin{array}{l}\text { Democratic Republic } \\
\text { of Congo }\end{array}$ & 15.87 & 17.01 \\
\hline Eswatini & 24.72 & 15.80 \\
\hline Lesotho & 14.09 & 13.44 \\
\hline Madagascar & 30.96 & 30.63 \\
\hline Malawi & 24.78 & 13.74 \\
\hline Mauritius & 49.17 & 40.53 \\
\hline Mozambique & 4.95 & 6.28 \\
\hline Namibia & 31.28 & 27.52 \\
\hline Seychelles & 30.68 & 24.00 \\
\hline South Africa & 33.34 & 33.34 \\
\hline Tanzania (Republic) & 19.53 & 39.12 \\
\hline Zambia & & 8.75 \\
\hline Zimbabwe & 31.81 & \\
\hline
\end{tabular}

In [13], the authors explains that the industrial sector has always been critical to the economic development of countries. Since the end of the 18th century, businesses have gone through enormous modifications that revolutionized a way how goods are produced and has yielded numerous benefits, predominantly related to efficiencies and productivity. In [14], the authors argues that presently, after three preceding industrial revolutions, the combination of advanced technologies and the internet age is completely transfiguring the industrial landscape and it is labelled the Fourth Industrial Revolution or its personification known as the Industry 4.0. The postal sector is not immune to these fastpaced technological revolutions that continue to chance the postal landscape daily.

The rise of digitalization brought upon the digital age has prompted the postal industry globally to enlarge their services further than the traditional mail delivery service of Posts. In [15], the authors hypothesise that with the global adoption of digitalization and digitization at an exponential rate, stakeholders are progressively demanding to interact directly with the postal service via digital networks.

\subsection{Industry 4.0}

In [13], the authors elucidates that the industrial sector has always been critical to the economic development of countries. Since the end of the 18th century, businesses have gone through enormous modifications that revolutionized a way how goods are produced and has yielded numerous benefits, predominantly related to efficiencies and productivity. In [14], the authors argue that today, after three preceding industrial revolutions, the combination of advanced technologies and the internet age is completely transfiguring the industrial landscape.

In [16], the authors argue that the aim of Industry 4.0 is to digitize and incorporate processes vertically across the entire value chain of the organisation, from conceptualization all the way to sales and after-sales support. Data throughout the value chain is available instantaneously, backed by augmented reality and optimized in a unified network Industry 4.0 is a farsighted initiative of the German State that traditionally supports advancement of the German industrial sector. In [17], the authors support this view and propose that in this sense, Industry 4.0 can be viewed as an action towards nurturing Germany's posture as one of the most leading technologically advanced nation.

In [18], the authors postulate that Industry 4.0 is envisioned at the fixated assemblage and application of prompt data and information by means of linking all individual rudiments of a system, with a view of reducing the intricacy of processes, while raising the efficacy and value of operations.

Figure 1 presents the Industry 4.0 framework and associated technologies at which the core of Industry 4.0 is based on the concept of the three underlying fundamentals which are:

- Digitalization and amalgamation of vertical and horizontal value chains

- Digitalization of offerings

- Digital industry models and client access

In [16], the author notes that the underpinnings to industry 4.0 could be elaborated as follows:

- Digitalization and amalgamation of horizontal \& vertical value chains comprise of two features; The initial feature comprises amalgamation of processes vertically across the entire firm and entails all business processes from conceptual 
design all the way to delivery of the product or service to the customer or end-user.

- Digitalization of offerings incorporates the extension of current offerings which includes the addition of smart sensors that could be utilized with data analysis tools as well as development of new digitized offerings. The ability to analyze big data could benefit firms to better respond to changing customer demands.

- Digital industry models and client access encompasses enlargement of offering by supporting disruptive digital solutions. Disruptive digital industry models have potential to create new revenue streams by responding with speed to the changing customer demand changes in a dynamic setting.

In [16], the authors argue that big data and data analysis tools are the principal competences of Industry 4.0 and is enabled by technologies such as smart sensors, advanced algorithms, Internet of Things, location technologies, and many other technologies that support the digital revolution.

Figure 1 presents the Industry 4.0 setting in which an argument is advanced that the crucial significance to Industry 4.0 is its ability to communicate with other smart "things" such as the digital capabilities of smart transportation, smart electrical grid, smart supply chain management, and other smart infrastructure. In [18], the authors argue that the linkage between social web and business web is of critical importance and will see further radical transformation in the future and will further reduce the digital divide between business and society at large as technology develops and becomes accessible to society.

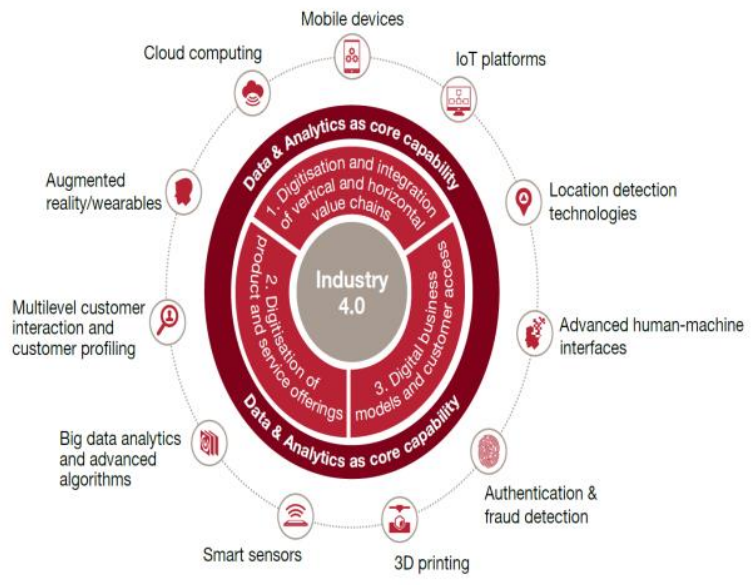

Figure 1: Industry 4.0 framework and contributing digital technologies [16]

In [19], the authors suggests that the important elements that outline the notion of Industry 4.0 are:

- Cyber-physical system (CPS), the term that describes the amalgamation of cyber with physical systems. CPS incorporates devices which can assemble and transmit data through the internet.

- Internet of things (IoT) facilitates the interaction with other systems and between systems and ultimately with the users.

- The ability to assemble data and analyze the data into useful information instantaneously is an important feature of a CPS and enables decision makers to make informed decisions.
In [20], the authors advocates that the concept of Industry 4.0 is underpinned by six design principles that are pertinent to its efficacious implementation in respective industries which are interoperability, virtualization, decentralization, real-time capability, service orientation and modularity depicted in Figure 2.

\begin{tabular}{|c|c|c|c|c|}
\cline { 2 - 5 } \multicolumn{1}{c|}{} & $\begin{array}{c}\text { Cyber-Physical } \\
\text { Systems }\end{array}$ & $\begin{array}{c}\text { Internet of } \\
\text { Things }\end{array}$ & $\begin{array}{c}\text { Internet of } \\
\text { Services }\end{array}$ & $\begin{array}{c}\text { Smart } \\
\text { Factory }\end{array}$ \\
\hline Interoperability & $\mathrm{X}$ & $\mathrm{X}$ & $\mathrm{X}$ & $\mathrm{X}$ \\
\hline Virtualization & $\mathrm{X}$ & - & - & $\mathrm{X}$ \\
\hline Decentralization & $\mathrm{X}$ & - & - & $\mathrm{X}$ \\
\hline Real-Time Capability & - & - & - & $\mathrm{X}$ \\
\hline Service Orientation & - & - & $\mathrm{X}$ & - \\
\hline Modularity & - & - & $\mathrm{X}$ & - \\
\hline
\end{tabular}

Figure 2: Design principle for each of the main 4 Industry 4.0 components [20]

The Fourth Industrial Revolution and its application as espoused by Industry 4.0 offers both challenges and opportunities for the postal sector, the major challenge is that Posts can no longer operate using business models of the past because digitalization of the Post is something that is not optional but mandatory if the Post still must survive another 100 years.

In [21], the authors argue that today, the concept of the internet is often reflected as "given" due to its omnipresent manifestation and quickening effect on the ways in which humanity relates. The world is changing rapidly because of the digital revolution. In [22], the authors argue that one such manifestation of the digital revolution is the IOT (Internet of things) with which digitization is no longer a simulated reality. IOT links several "things" through the internet and allows them to communicate information amongst each other. In [23], the authors propose that the Internet of Things (IoT) is sensor technologies that enable physical objects to gather and transmit data through the Internet in instantaneously. It is one of the latest advances taking hold in many industries and most appropriate for the postal sector due to its possible applications in the postal value chain.

In [24], the authors propose that the IoT architype is envisioned at devising a sophisticated system with the combination sensors and associated technologies with ability to communicate in realtime. Contrarywise, assembling data and preserving the privacy of users, and then taking cognizance of confidentiality and internet security specification in IoT remains a significant concern amongst stakeholders in the IoT space.

In [23], the authors suggests that the current rise of IoT applications is fuelled by a conjunction of issues such as omnipresent connectivity and the diminishing expenditure and enhanced performance of measuring devices (sensors) and analytics. These technology developments relate to expanding consumer requirement for more data on the products and services they purchase. The flow of information is crucial to the "flow of things".

The United States Postal Service has embodied the Internet of Things (IoT) and coined the Internet of Postal Things (IoPT). In [23], the authors articulate a postal standpoint and reason that IoT can be better pronounced as "Things on the Internet" which are 
unified webs of distinctively recognized physical "things" embedded with sensors that amass, converse, and act upon a widespread diversity of data such as locality pin-pointing, temperature, and movement. These "smart objects" amass and transmit data that can be scrutinized for improvement of business processes across organizations and for improved solutions to customer demands. Figure 3 depicts the chief elements of the IoT value-chain.

In [23], the authors argue that IoT unwraps new opportunities for various organizations and in particular entities like the postal service which has a geographic reach that surpass many industries. In [25], in the authors propose that the postal service world-wide has a widespread network of over 677,000 post offices, 5.32 million staff and physical network of buildings encompassing 192 countries and asserts that the postal sector performs a significant socio-economic role in society at large.

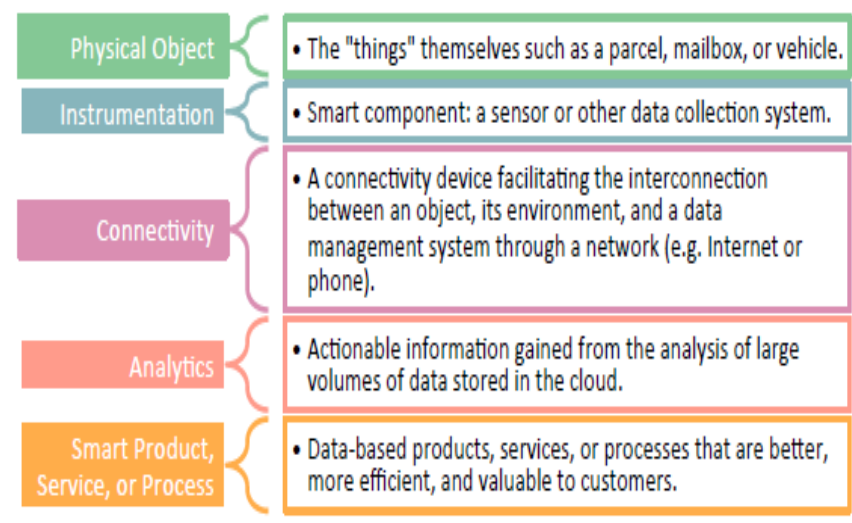

Figure 3: IoT value chain [23]

Posts could significantly profit in implementing Industry 4.0 fundamentals in the quest to adapt to challenges and opportunities presented by the digital era, and could greatly improve service delivery to new market demands and improve their sustainability (both economic, social and environmental). Applications of Industry 4.0 fundamentals can significantly improve sustainability of Posts in Southern Africa.

\subsection{Innovation Diffusion Theory}

In [26], the authors postulates that the most noticeable and dominant attempt to dissect the dynamics influencing the adoption and diffusion practices was pioneered by [27], however the authors argue that the framework is appropriate for conceptualization of adoption and diffusion from a qualitative point of view as opposed to quantitative prediction of adoption of innovative practices. In [28], the author argues that diffusion is the process by which an invention is conversed through networks over time amongst the participants of a network. In [29], the authors argue that technology adoption is a developed area of research in information systems (IS).

In [30], the authors articulates the difference between innovation and technology which is often confused and argues advance that technology is concerned in resolving real social problems to advance humanity. In [31], the authors argue that innovation on the other hand comprises of the creation of an innovative concepts and development of the concept into new offerings resulting in economic development. In [32], the authors argue that innovation is not merely creativity, research and development, invention, bright ideas or fancy gadgets. In [33], the authors argue that innovation is rather a development of new resources or new resource capacity that are able to create wealth. In [34], the authors argue that innovation is a complex, organization-wide effort, that demands a set of procedures and activities to shape, coordinate, and promote it.

In [28], the authors investigates drivers that define the speed of acceptance (adoption) of innovations and argues that the following factors regulate the degree of adoption. (a) Apparent characteristic of innovation affected by considerations such as relativity of the advantage to adopt, compatibility of adoption to current systems, complexity of the innovation, trialability of the innovation, and observability of the results. (b) Innovation choice, which is driven by issues such as is the innovation optional or mandatory (c) Type of societal structures including a component such as the degree of linkages of the societal structures; and (d) The effectiveness and efficiency of transformation (change) champions in advocating transformational change.

In [11], the authors suggests that each invention has distinctive attributes that affect the dispersion (diffusion) process. These attributes can be broken-down into five elements:

(a) Relative advantage is the extent to which an invention is understood as being superior to the concept it succeeds, typically stated as cost-effectiveness, societal stature, or other advantages.

(b) Compatibility as recognized by participants in society is constructively related to the level of acceptance (adoption) and influences the way customers act towards an invention.

(c) Complexity is the extent to which an invention is understood as comparatively complicated to comprehend and utilize.

(d) Trialability is the extent to which an invention may be tested on a restricted basis. The trialability of an invention is certainly related to the pace of acceptance (adoption).

(e) Observability is the extent to which outcomes are observable to the user and to others.

\subsection{Technology Adoption Theory}

In [35], the authors argues that Theory of Reasoned Action (TRA) is the early notion that attempted to explain user adoption of technology. TRA describes user behaviour from a social point, and with a specific aim of pin-pointing the causes of conscious behaviour. In [36], the authors propose that the model (Technology Acceptance Model- TAM) was developed from TRA as its basis but further refined.

In [37], the authors argues that the basis of TRA is that behaviour is predicted by intention (I) and further highlights that intentions are conjointly driven by two factors (a) Attitude (A) towards the act which is a function of attitudes about effects of this conduct and (b) subjective norms (SN) defined as a person's viewpoint of whether stakeholders key to the person consider the actions should be implemented. Attitude towards the behaviour is defined as the individual's negative or positive outlook about executing the behaviour. 
In [38], the authors propose that TRA contends that views influence mindsets, which lead to intent and as a result engender behaviour. The TRA is graphically illustrated in Figure 4.

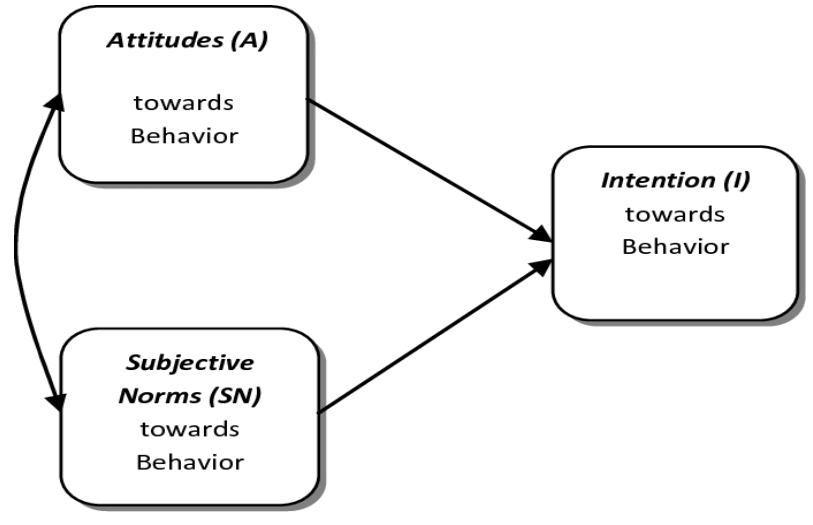

Figure 4: Theory of reasonable action. Source [37].

In [39], the authors state that consumer rationale to accept and adopt a technology could be explained by perceived usefulness (PU), perceived ease of use (PEU) and attitude towards the system. In [39], the authors hypothesize that attitude of a user towards the system was the core factor to determine if the user will accept or reject the innovation, and that attitude is directly influenced by (a) Perceived Usefulness (PU) and (b) Perceived Ease of Use (PEU); and concludes that apparent ease of use unswervingly influence perceived usefulness.

In [38], in the authors argue the concepts in the earliest TAM (see Figure 5) as follows: Perceived Usefulness (PU), Perceived Ease Of Use (PEOU), Attitude, and Behavioural Intention to Use. Among the constructs, PU and PEOU establish a user's confidence on a technology and consequently predict his or her stance on the technology, which in turn foresees its approval.

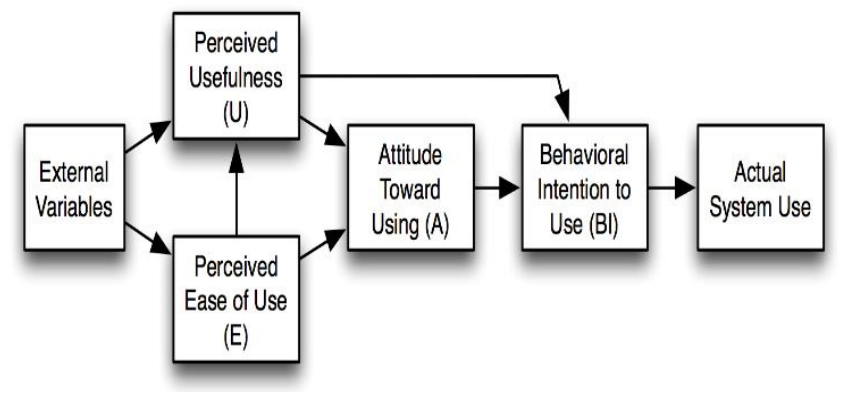

Figure 5: Technology Adoption Model. Source [38]

In [40], the authors maintains that while the TRA was intended to illuminate essentially any human behaviour, the TAM on the other hand was intended to offer an clarification of the factors of computer acceptance throughout a comprehensive range of enduser computing technologies and user populations. In [37], the authors subsequently contends that according to the TAM, actual system usage is directly defined by behavioural intention (BI) to use. BI is in turn swayed by the user's mindset towards utilizing the system and perceived usefulness. Attitude is propelled by perceived usefulness (PU) and perceived ease of use (PEOU) of the system. Both PU and PEOU are influenced by external variables, such as individual variations, situational constrictions, organizational traits, and system attributes.

www astesj.com
As the TAM progressed past its initial positioning, several researchers established shortcomings in the model which required to be tackled. The outcome of research that was conducted by several researchers ensued in adjustments to TAM. In [37], the authors suggest that the adjustments entailed the establishment of additional variables and concepts resulting in TAM2 as depicted in Figure 6.

In [37], the authors argue that the major additions to the TAM that were introduced by TAM 2 were the inclusion of societal influence activities (subjective norm, voluntariness, and image) and mental method procedures (job relevance, output quality and results demonstrability).

TAM2 theorizes that users' mental assessment of the match between considerable goals at work and the subsequent effects of executing tasks using the system provides a basis for establishing views concerning the usefulness of the system. The results of the research by uncovered that TAM 2 performed well in both voluntary and obligatory environments.

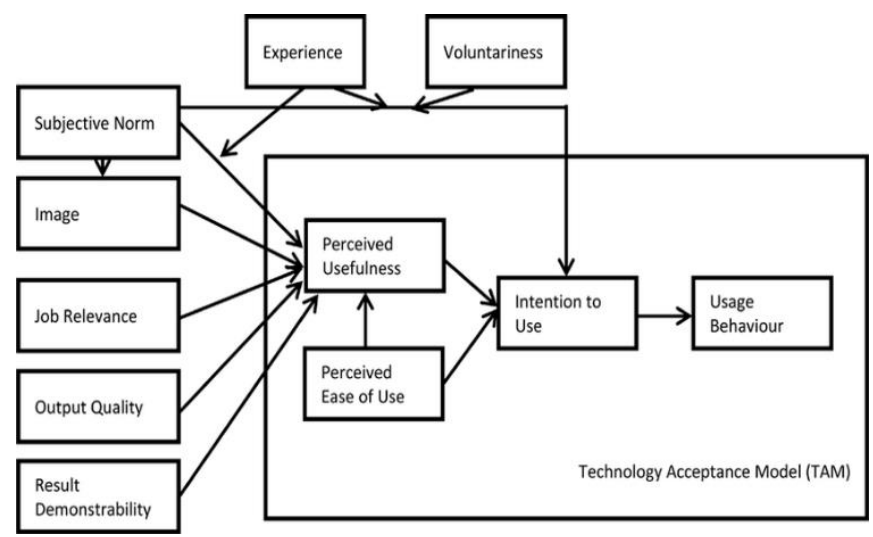

Figure 6: Technology Adoption Model 2. Source [42].

In [37], the authors argues that the succeeding foremost addition to TAM was the Unified Theory of Acceptance and Use of Technology (UTAUT), the author further proposes UTAUT was framed, with four fundamental determining factor of intention and usage and up to four moderators of crucial relations. The theory proposed that four important concepts perform a significant part as direct factors of user acceptance and usage behaviour: (a) performance expectancy (b) effort expectancy (c) social influence and (d) facilitating conditions. The UTAUT is presented in Figure 7.

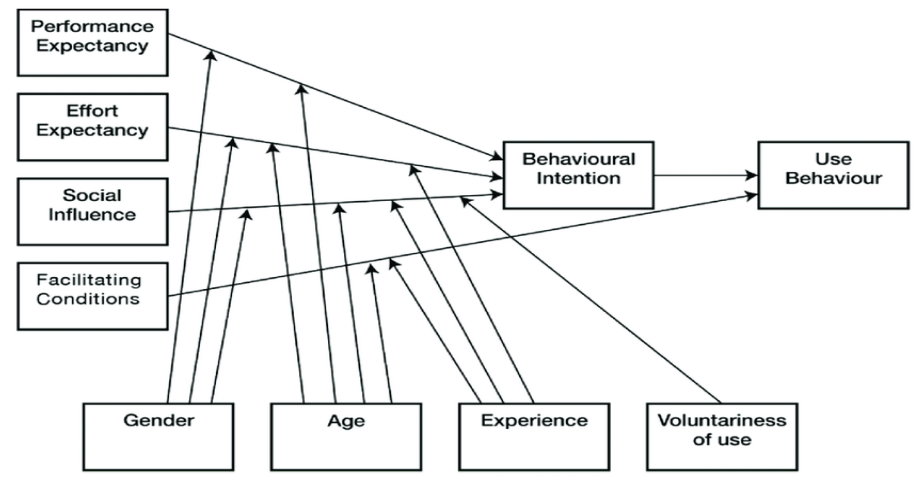

Figure 7: Unified Theory of Acceptance and Use of Technology (UTAUT. Source [43]. 
In [37], the authors propose that UTAUT advocates that facilitating conditions would unswervingly impact usage, while the remaining three concepts would influence Behavioural Intention (BI). In [44] the authors argue that the model describes facilitating conditions as the extent to which a person deems that organizational and technical infrastructure exists to support the utilization of a system they are accepting (adopting). In [45], the authors argue that the UTAUT further extended the concepts in the earliest TAM through the recognition of the vital role of endeavour in performing the new task and the role support structures determines adoption in organizations.

In [46], the authors argues that TOE (TechnologyOrganization-Environment) framework entails three categories of settings that may influence technological innovation adoption and implementation process. TOE is premised on the three context which are technological, organizational, and environmental. In [47], as represented in Figure 8, the authors explains that technological setting defines the internal and external technologies suitable to the organization, while organizational setting denotes descriptive actions about the organizational scope, size and structure; finally, environmental setting is the arena in which an organization conducts its business.

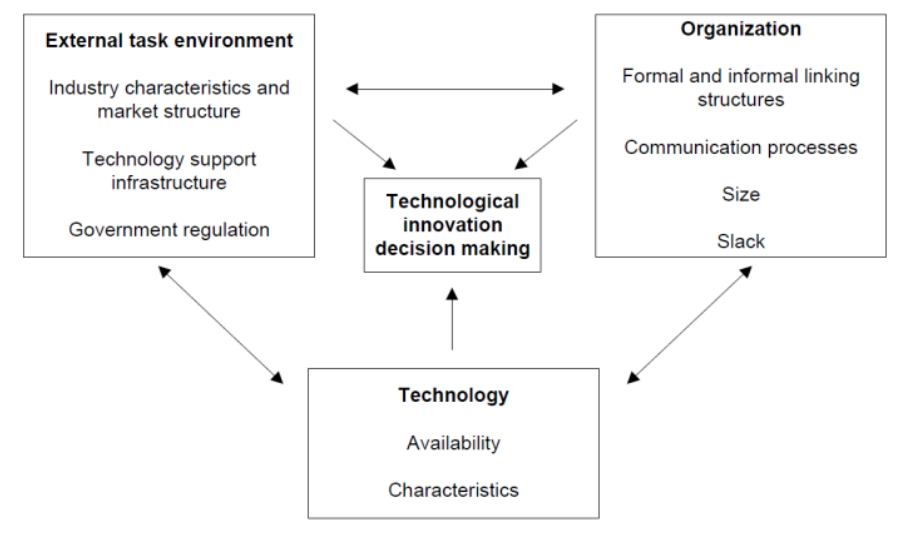

Figure 8: Technology, organization, and environment framework

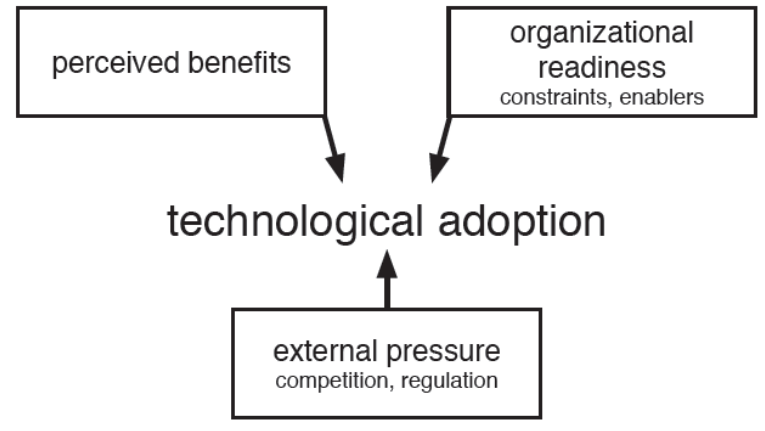

Figure 9: BOE Model [48]

In [48], the authors postulates that the TOE model defines the dynamics for technological adoption, focusing on the external stresses (e.g. market forces and governmental regulatory requirements), organizational structures, and technological availability; in addition the BOE model was originally developed to understand the adoption of EDI (electronic data interchange) technology, but has since been used as a general technology adoption model. The BOE model comprises three factors: external pressure, organizational readiness, and perceived benefits.

In [48], the authors advance that by distinction, the BOE model as illustrated in Figure 9 (Benefits, Organizational Readiness and External Pressures) integrates the organization and technology context of TOE into organizational readiness and augments a perceived benefit aspect for viewing at adoption of technology.

In [26], the authors argue that the Adoption and Diffusion Outcome Prediction Tool (ADOPT) was developed as a tool to encourage application in project planning and implementation of sound insight of the social and economic factors affecting acceptance (adoption) of agricultural innovations. In [49], the authors proposes that ADOPT focuses on factors that have demonstrated to impact the pace and/or highest point of adoption within a population. These are (a) attributes of the innovation, (b) attributes of the population, (c) tangible relative advantage of employing the innovation, and (d) learning of the actual relative advantage of the technology. In [26] the authors proposes that the variables of the theoretical context can be divided into two main categories: (a) those that relate to traits of the target population, and (b) those that relate to traits of the practice. These elements are presented in Figure 10.

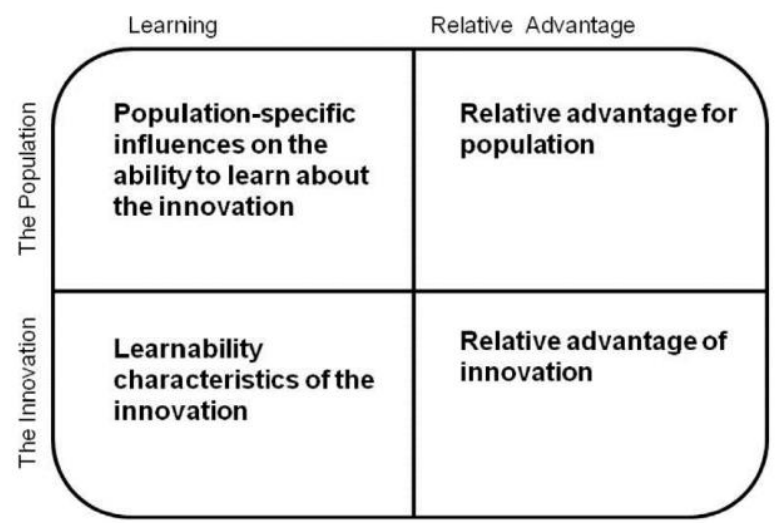

Figure 10: Conceptual characterization of factors included in ADOPT

\subsection{Capability Maturity Models}

In [50], the authors states that the original Capability Maturity Model (CMM) was developed in the software engineering space to support advances in the dependability of software development organizations, that is, in their aptitude to deliver software within time, performance, cost and quality. More specifically, it was "intended to assist developers to choose process-improvement strategies by defining their existing process maturity and finding the most critical issues to improving their software quality and process".

In [51], the authors describes the five maturity levels and further emphasize the basic process changes made at each level:

- Initial: The process is described as ad hoc, and sporadically even anarchic. Limited processes are defined, and accomplishment depends on individual effort.

- Repeatable: Fundamental business processes are established to track expenditure, plans, and functionality. 
- Defined: The business processes are documented, standardized, and integrated.

- Managed: Detailed measures of the business processes are collected. Business processes are quantitatively understood and controlled.

- Optimizing: Continuous process improvement is enabled by quantifiable feedback from the business process.

The CMM provides a framework for shaping these incremental steps into five maturity levels that lie down consecutive grounds for continuous process improvement. These five maturity levels characterize an ordinal scale for evaluating the maturity of an organization's processes and for appraising its process capability. The levels also help an organization highlight its improvement endeavours. The steps above are graphically presented in Figure 11.

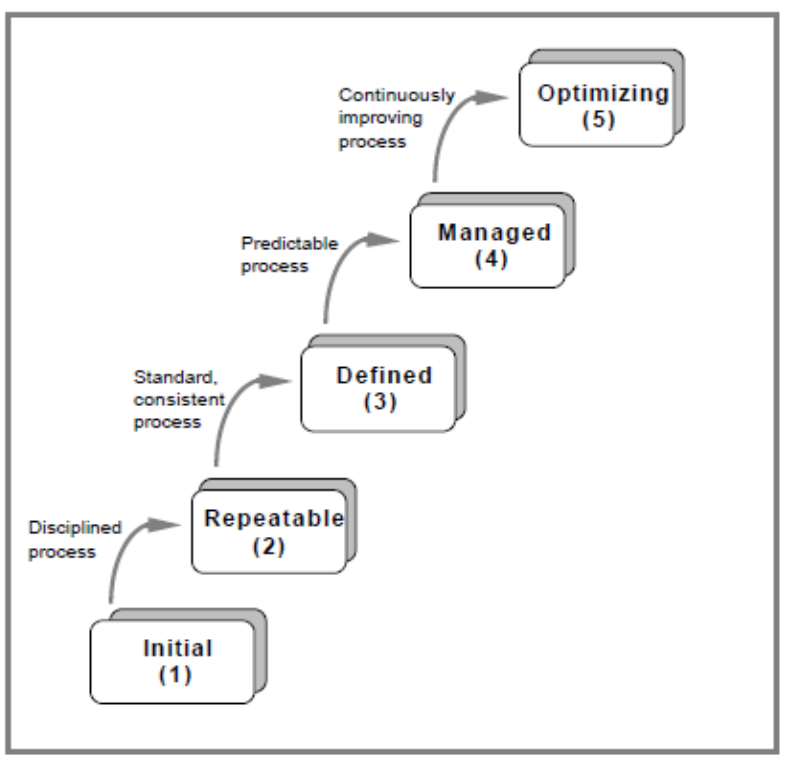

Figure 11: The five levels of software maturity [51]

In [52], the authors argue that capability maturity models are used in three ways; (a) Descriptive use which focuses on (1) To assess the 'as-is' state of specific organizational capabilities (2) As an analytical diagnostic tool (3) To communicate maturity levels to internal and external stakeholders (b) Prescriptive use which focus on (1) To ascertain desired maturity level and receive guidance on how to continuously improve from current to desired level (2) To follow specific and detailed sequences of action (3) Comparative use which emphasizes on comparing the performance of the specific organisation through internal or external benchmarking (best practices).

In [53], the authors affirms that one of the barriers to industry's wider headway in digital transformation is the absence of a vivid industry focused blueprint. The report proposes that the Digital Maturity Model presented in Figure 12 is a valuable instrument to offer guidelines for a vivid pathway throughout the transformation journey.

The five core dimensions underpinning the model are:

- Customer, this facet is focused on offering an understanding where consumers perceive the organization as their digital collaborator utilizing their desired networks of interaction to control their connected future on and offline

- Strategy, this facet stresses on how organizations transform or operate to enhance its competitive advantage through digital projects; it is entrenched within the whole organizational strategy

- Technology, this facet emphasizes the success of digital strategy by enabling the creation, processing, storage, securing and transmission of data to meet the needs of customers effectively and efficiently.

- Operations, this facet is premised on executing and evolving processes and tasks by leveraging on digital technologies to drive strategic management and enhance business efficiency and effectiveness

- Organization and culture, this facet focuses on identifying and cultivating an organizational culture with governance and talent management processes to boost advancement along the digital maturity curve, and the ability to realize expansion and invention (innovation) goals.

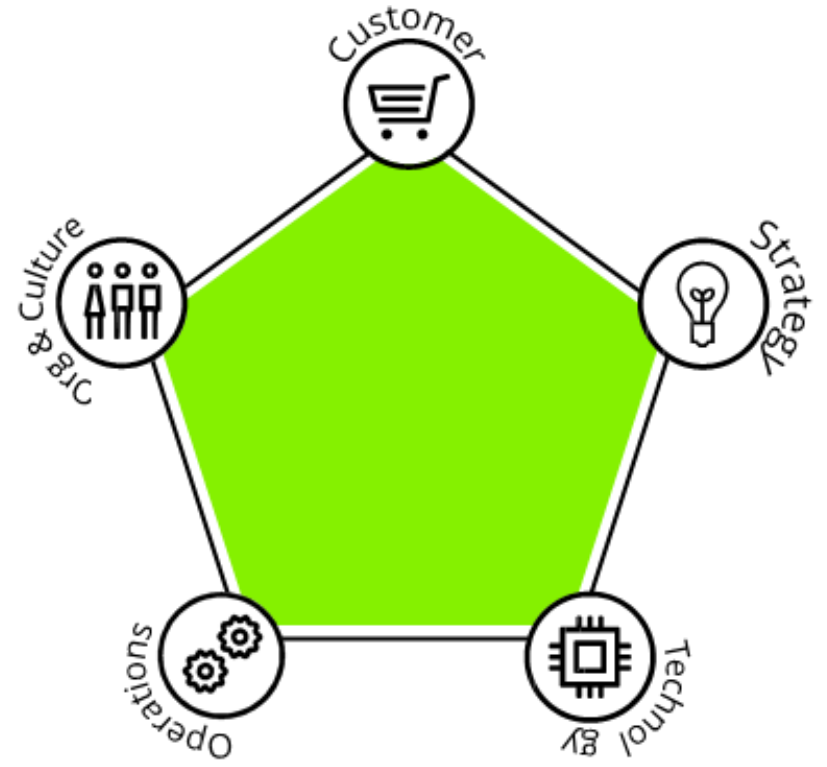

Figure 12: Deloitte Digital Maturity Model [53]

Figure 13 crystalizes the sub-dimensions that are associated with the five core dimensions presented in Figure 12. The subdimensions elucidate and unpacks each of the five core dimensions that are critical to digital transformation, these dynamics are such as customer engagement, customer insight and behaviour, brand management, finance \& investment, connected things, data \& analytics, real-time insights \& analytics, agile change management, organizational culture, leadership \& governance, organizational design \& talent management, workforce enablement, automated resource management, stakeholder management, ecosystem management, strategic management, customer trust \& perception, market \& customer, network, security technology architecture and innovation management are key towards a successful digital transformation journey.

In [52], the authors propose a Digital Maturity Model which consists of four stages. The stages proposed in their model are (a) Initiate (b) Competent (c) Purposeful and lastly (d) 
Transformative. The key attributes of businesses related to each of these maturity stages are presented in Figure 14.

\begin{tabular}{|c|c|c|c|c|}
\hline Customer & Strategy & Technology & \begin{tabular}{|l} 
Operations \\
\end{tabular} & $\begin{array}{l}\text { Organisation \& } \\
\text { Culture }\end{array}$ \\
\hline $\begin{array}{l}\text { Customer } \\
\text { Engagement }\end{array}$ & Brand Management & Applications & $\begin{array}{l}\text { Agile Change } \\
\text { Management }\end{array}$ & Culture \\
\hline $\begin{array}{l}\text { Customer } \\
\text { Experience }\end{array}$ & $\begin{array}{l}\text { Ecosystem } \\
\text { Management }\end{array}$ & Connected Things & \begin{tabular}{|l|} 
Automated \\
Resource \\
Management \\
\end{tabular} & $\begin{array}{l}\text { Leadership and } \\
\text { Governance }\end{array}$ \\
\hline $\begin{array}{l}\text { Customer Insights } \\
\text { \& Behaviour }\end{array}$ & $\begin{array}{l}\text { Finance \& } \\
\text { Investment }\end{array}$ & Data \& Analytics & $\begin{array}{l}\text { Integrated Service } \\
\text { Management }\end{array}$ & $\begin{array}{l}\text { Organizational } \\
\text { Design \& Talent } \\
\text { Management }\end{array}$ \\
\hline \multirow[t]{4}{*}{$\begin{array}{l}\text { Customer Trust \& } \\
\text { Perception }\end{array}$} & Market \& Customer & \begin{tabular}{|l|} 
Delivery \\
Governance \\
\end{tabular} & $\begin{array}{l}\text { Real-time Insights } \\
\text { \& Analytics } \\
\end{array}$ & \begin{tabular}{|l|} 
Workforce \\
Enablement \\
\end{tabular} \\
\hline & $\begin{array}{l}\text { Porffolio Ideation \& } \\
\text { Innovation }\end{array}$ & Network & $\begin{array}{l}\text { Smart and Adaptive } \\
\text { Process } \\
\text { Management }\end{array}$ & \\
\hline & $\begin{array}{l}\text { Stakeholder } \\
\text { Management }\end{array}$ & Security & \begin{tabular}{|l|} 
Standards \& \\
Governance \\
Automation
\end{tabular} & \\
\hline & $\begin{array}{l}\text { Strategic } \\
\text { Management }\end{array}$ & $\begin{array}{l}\text { Technology } \\
\text { Architecture }\end{array}$ & & \\
\hline
\end{tabular}

Figure 13: The 5 core dimensions divided into 28 sub-dimensions [53]

In [54], the authors suggests that the use of maturity models to the Industry 4.0 phenomenon could potentially aid corporations to assimilate this practice into their ethos and argue that the Industry 4.0 vision portrays a completely new approach to business process and a completely new business model. They propose a three-step systematic process to guide organizations in their respective Industry 4.0 journey to find footing and determine their vision which is precursor for strategy.

In [54], the authors proposes that the three-stage process comprise of (a) Envision 4.0 which relates to defining a tailormade Industry 4.0 vision and it requires companies to develop their comprehension of the generic Industry 4.0 concepts with company-specific proficiencies and resources (b) Enable 4.0 starts with the significant Industry 4.0 vision developed in the previous phase, and based on this vision, the organization defines the digital portfolio and proficiencies required to provide support to the new products or services identified. (c) The enact phase is characterized by a well-timed, directed and multi viewpoint plan of the overall strategy towards the Industry 4.0 vision that fosters the strategic setting for tangible measures and outcomes.

In [54], the authors further argue that in order to employ maturity models to execute the three-staged process described earlier in the context of Industry 4.0, the maturity gauges (scales) for the three-stage model are described as follows: (a) Level 1 represents "initial" level where there is no industry 4.0 vision in place, (b) Level 2 represents "managed" level whereby a Roadmap of industry 4.0 strategy is in place, (c) Level 3 represents "defined" level whereby customer sections (segments), value intention (proposition), and significant (key) resources and competencies are clearly defined; (d) Level 4 which represents "transform" level whereby strategic imperatives are transformed into tangible projects, and lastly (e) Level 5 which represents "Detailed Business Model" level whereby the business model is completely transmuted in line with Industry 4.0 objectives.

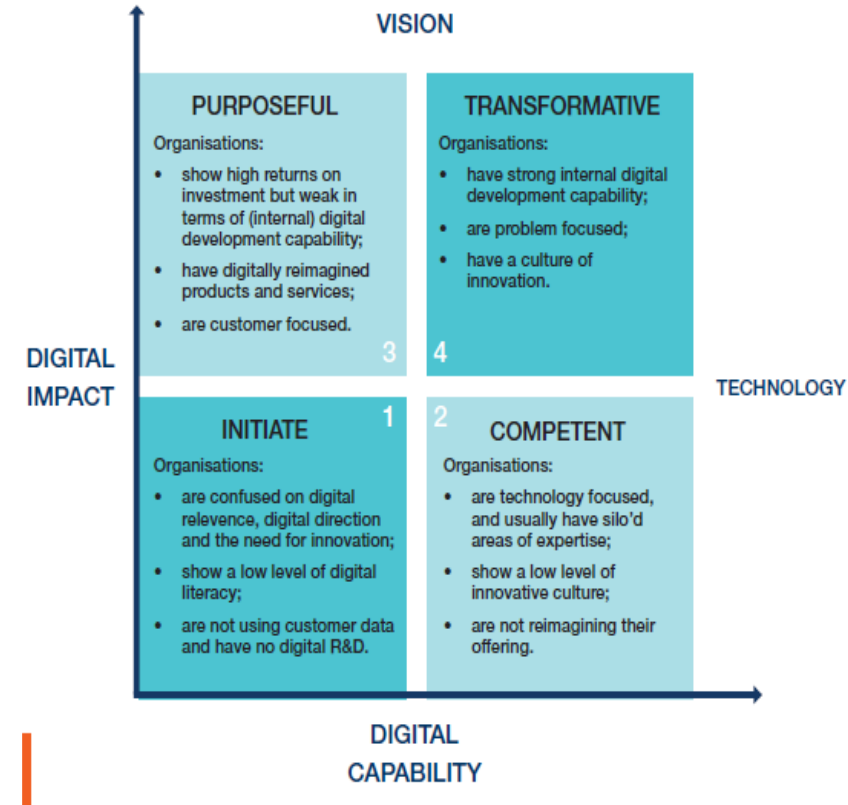

Figure 14: Stages of Digital Maturity and Key Attributes of Businesses in Each Maturity Levels [52]

\subsection{Barriers towards movement to digital Post}

In [15], the authors articulates the top five barriers (obstacles) towards movement into digital Posts by Region and for purposes of this study only the top performers (Industrialized countries) and Africa will be considered. These barriers are tabled in Table 3 .

Table 3: Barriers for digital adoption and diffusion in the postal sector [15]

\begin{tabular}{|l|l|}
\hline $\begin{array}{l}\text { Geographic } \\
\text { area }\end{array}$ & Barriers \\
\hline Globally & Resource constraints \\
\cline { 2 - 2 } & Transition towards a digital culture \\
\cline { 2 - 2 } & $\begin{array}{l}\text { Limitations of IT infrastructure } \\
\text { required for development of digital } \\
\text { services }\end{array}$ \\
\cline { 2 - 2 } Industrialized & $\begin{array}{l}\text { On-time custom clearance capability } \\
\text { and capacity }\end{array}$ \\
\hline Africa & $\begin{array}{l}\text { The time taken for the corporation to } \\
\text { shift in the direction of a digital culture }\end{array}$ \\
\cline { 2 - 2 } & $\begin{array}{l}\text { Slow overall consumer embracing of } \\
\text { digital postal services }\end{array}$ \\
\hline & Limited resources \\
\cline { 2 - 2 } & Lack of IT infrastructure \\
\cline { 2 - 2 } & Poor digital culture \\
\cline { 2 - 2 } & $\begin{array}{l}\text { Lack the internal resources to develop } \\
\text { digital services }\end{array}$ \\
\cline { 2 - 3 } & $\begin{array}{l}\text { Slow overall consumer embracing of } \\
\text { digital postal services }\end{array}$ \\
\hline
\end{tabular}

Clearly, Africa is faced with a plethora of challenges as depicted in Table 3, and Southern Africa as a Region in Africa suffers from the same challenges. In [8], the authors hypothesises that inadequate internet connectivity, inadequate capital outlay and 
or recapitalization of the network infrastructure, meagre excellence of service, inadequate interoperability and connectivity among the business value chain and vagueness in postal sector definition in Southern Africa are proposed as foremost motives for the low advancement of the Region in embracing technologies associated with the digital revolution.

In [15], the authors affirms that the best ranking designated operator when it comes to digital readiness achieves a normalized score of 1 , while the lowest possible performer obtains a normalized minimum score of 0 . All normalized scores can be understood as the gap of any given designated operator with respect to the best (score 1), the midway (score above 0.5 ) or the worst (zero score) global performer. Table 4 represents the postal digital readiness of the industrialized countries with Switzerland leading with a full score of 1 while Table 5 portrays Southern Africa as a region and South Africa leads with a score of 0.46 which is just below the intermediate score of 0.5 while the worst performing countries are Madagascar and Democratic Republic of Congo which are both at 0.05 . The distance between the worst performer and the best performer stands at a mammoth gap of 0.95 . Clearly Southern Africa is faced with enormous challenges to realize a digital Post.

Table 4: Digital readiness score of Industrialized countries [15]

\begin{tabular}{|l|l|}
\hline Country & Normalized score 2019 \\
\hline France & 0.81 \\
\hline Germany & 0.81 \\
\hline Japan & - \\
\hline Netherlands & 0.62 \\
\hline Switzerland & 1.00 \\
\hline
\end{tabular}

Table 5: Digital readiness score of Southern Africa countries [15]

\begin{tabular}{|l|l|}
\hline Country & $\begin{array}{l}\text { Normalized score } \\
\mathbf{2 0 1 9}\end{array}$ \\
\hline Angola & - \\
\hline Botswana & 0.32 \\
\hline Comoros & 0.14 \\
\hline $\begin{array}{l}\text { Democratic Republic of } \\
\text { Congo }\end{array}$ & 0.05 \\
\hline Eswatini & - \\
\hline Lesotho & 0.19 \\
\hline Madagascar & 0.05 \\
\hline Malawi & 0.08 \\
\hline Mauritius & - \\
\hline Mozambique & 0.11 \\
\hline Namibia & 0.27 \\
\hline Seychelles & - \\
\hline South Africa & 0.46 \\
\hline Tanzania (Republic) & 0.22 \\
\hline Zambia & - \\
\hline Zimbabwe & 0.14 \\
\hline
\end{tabular}

The literature has pointed out that adoption of technology of organizations in general or digitalization (Adoption of digital technologies) of the Post is a complex non-linear phenomenon with a variety of drivers and barriers. Adoption and diffusion barriers and drivers reveal a systemic character, which demands an all-inclusive approach to managing the complex nature of adoption and diffusion barriers and drivers that involve exploration of interactions between adoption and diffusion barriers and drivers as well as management of the casual relationship between the drivers and barriers of adoption and diffusion of technology/digitalization.

\subsection{From reductionist to system thinking approach}

In [55], the authors explains that reductionism is understood as the conventional means of tackling problem solving and is widespread throughout numerous fields. Reductionism also goes under many names including 'stepwise enhancement', 'disaggregation' and merely 'breaking problem into subproblems'. Reductionism inclines to refer to comprehension instead of problem-solving but the latter seems more appropriate in this case. In [56], the authors argue that reductionism as the opposite of holism and systems thinking agrees with the view that all objects or systems are breakable to lower levels in the hierarchy of their composition.

In [57], the authors contends that in accordance with reductionist thinking "The whole can be broken down into its parts and put back together from its parts. Parts are related through a simple cause-effect relationship; Thus, its defining characteristics exist in its parts." However, there are limitations to a reductionist thinking approach because systems most often defy the reductionist analysis because by focusing on the system's parts, researchers miss the whole, which frequently took on a form that was not distinguishable from the reconstructed parts. This view can be interpreted that it assumes that for a system to perform effectively and efficiently, its components (parts) should perform effectively and efficiently.

Conversely, systems are complex and as result the interaction of the components (parts) in a dynamic setting invariably affect performance of the entire (whole) system. Therefore, effective, and efficient technology adoption must focus on the dynamic setting (interaction) of drivers and barriers rather than on their separate actions. In [58], the authors argue that system is a unified set of components that are logically organized in a way that achieves a particular objective. In [59], the authors proposes that a system is a sequence of intermingling components organised to achieve stated goals.

In [60], the authors suggests that there are key dissimilarities in behaviours of reductionist thinkers when contrasted with systems thinkers and the crux of the differences is that while a reductionist approach simplifies the problem to its smallest essence to enable resolution of the problem through analytical methods; a system thinking approach on the other hand seek to understand the bigger picture and how elements of the problem interact in a dynamic setting. Because organizations are complex due to many interacting dynamics and forces, it is probable to propose that postal sector in Southern Africa lags in adoption of innovative technologies due to its reductionist thinking approach rather than a system thinking approach.

In [61], the authors propose that an event-oriented viewpoint is logical, action-oriented, irresistibly uncomplicated and frequently narrow-minded. Figure 15 portrays this thinking as a concept. In [62], the authors further argues that this event-oriented mind-set 
signifies a conviction that challenges are irregular, emanating from overwhelming events in the outside world and that life is unpredictable. He argues that this mind-set has a conviction that events pop out from nowhere or at least there is no time to worry about their causes, what is important he argues, is to fix the problem as soon as possible. The typical thinking is characterized by linearity whereby problems are events and solutions as fixes.

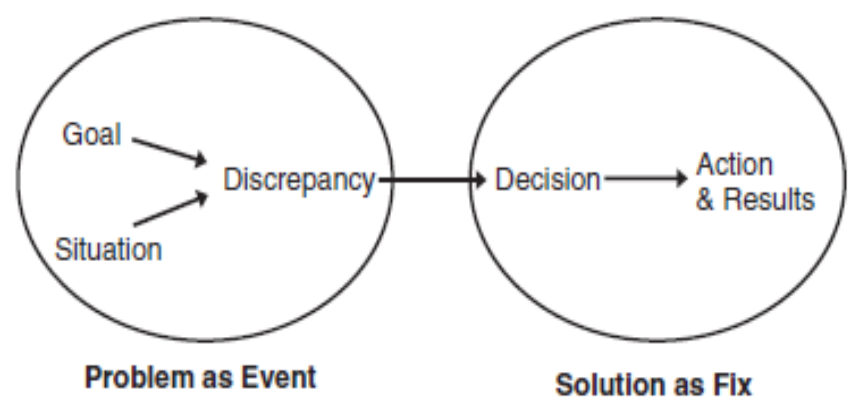

Figure 15: Event oriented worldview [62]

In [62], the author contends that feedback systems thinking is paradigm shift, a new approach of understanding the world, and a remedy to narrow thinking; and further advances that problems and solutions are viewed as intertwined as depicted in Figure 16.

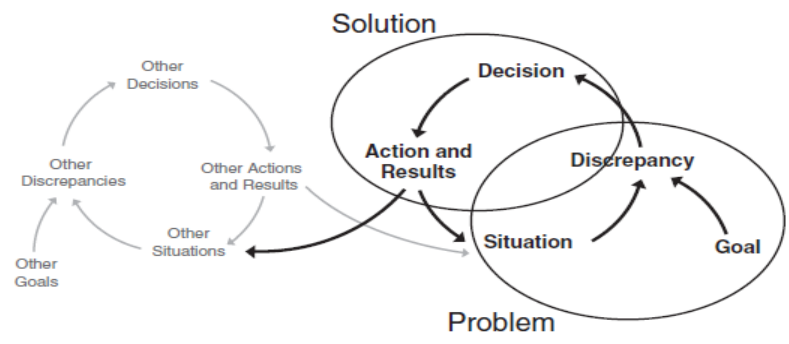

Figure 16: A shift of mind: A feedback perspective [62]

In [61], the authors contends that the change is the ultimate constant, and that change confronts conventional traditions, methods, and values. Important, most of the changes we battle to grasp occur as after-effects, deliberate, and not deliberate. In many cases, well-intentioned exertions to resolve unrelenting problems often lead to policy resistance, where policies are overdue, weakened, or thrashed by the unanticipated reactions of other people or of nature. This is a frequent challenge in the postal sector globally, in Africa and for purposes of this study in Southern Africa where for instance the digital age has brought unintentional consequences of the archaic postal business models that are putting in peril the very survival of postal operators.

In [63], the authors affirm that a system thinking approach is different from a reductionist approach, the reductionist approach focuses on analysis which is about dissection of complexity into manageable components or an event-oriented approach which has the conviction that problems emanate from nowhere. This approach clearly fits into the linear and mechanistic worldview, where the world and problems are fragmented into parts. Diametrically opposed to a reductionist approach of "analysis" is systems thinking approach which relies on synthesis rather than analysis. Fusion (synthesis) relates to comprehending the whole and the fragments (parts) simultaneously, alongside the relationships and links that constitutes the dynamic setting of the whole.

In [57], the authors supports this notion and argues that the whole emanates because of the interfaces between its components or fragments and proposes that fragments are related through intricate multiple effects. Thus, its defining attributes do not live in its fragments but in the whole. In [60] the authors suggest that systems thinking means the aptitude to distinguish and analyse the inter-connections within and between systems.

In [64], the authors contend that system thinking is a strong approach to deal with the system of innovation. In [64], the authors defines systems thinking as a field for observing aggregates and a context for spotting interrelatedness rather than things, for spotting patterns of change instead of stagnant snapshots. In [65], the authors define system thinking as the capability to epitomize and measure dynamic intricacy (e.g., behaviour that develops from the interface of a system's agents over a period), of systems.

In [66], the authors maintain that systems thinking is a set of harmonious diagnostic competencies used to enhance the ability to discover and comprehend systems, forecasting their conducts, and developing adjustments to them to create the anticipated effects. These competencies act as a system. In [63], the authors suggest that systems thinking is a process of examining and improving mental models and its core is based on four fundamental concepts (a) connectedness (b) Synthesis (c) Feedback loops, and lastly (d) Causality

In [60], the authors suggest that Systems Thinking requires recognition that systems designed by humans, recurrent occurrences or relations originate from systemic constructs which emanate from mental models. In [60], authors further propose that the Iceberg Model (Depicted in Figure 17), is a fundamental aspect of systems thinking. The Iceberg Model contends that actions (events) and patterns (which can be observed) are triggered by universal (systemic) structures and mental models, which are usually not observable.

In [60], the authors further propose that systemic constructs as in structures are the structural pyramid; societal order; interrelatedness; instructions and techniques; establishments and endorsement levels; process flows and methods; enticements (incentive programme), reward (compensation), aims, and system of measurement (metrics); manners (attitudes); responses and the incentives and qualms that cause them; organizational culture; feedbacks and interruptions (delays) in a dynamic setting; and fundamental forces that occur in organizations. Behaviours develop from these complex interactions, which exist because of mental models.

In [67], the authors argue that system dynamics, a subset of systems thinking signifies variations in a complicated system, and is beneficial for mimicking the stock-flow-feedback processes that usually trigger the behaviour of intricate systems. In [68] the authors argues that the modelling approach depend on the following crucial elements. "Stocks" exemplify the rise of something; "flows" exemplify the rate of flow into or out of a stock. 


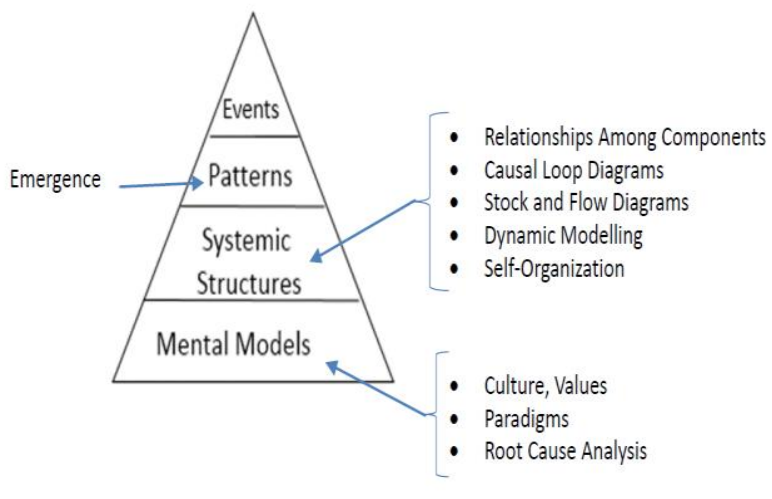

Figure 17: Integrated Model of Systems Thinking [60]

Stocks and flows, and variables characterises a system of linked non-linear differential equations, which can be modelled over a period to ascertain how stocks shift over time. In [69] the authors argues that one benefit of application of system dynamics approach over more conventional models is the addition of feedback consequences. Feedbacks ensure that a model's output is precise and uncovers intricacy that could be unobserved in other modelling approaches. Therefore, decision-makers can more definitely distinguish the interrelatedness of the model in a dynamic environment.

In [69], the authors argue that learning is a response (feedback) process. In [67], the author argues that as decisions are made these action modify the real world, and information feedback about the real world is received; and applying new insights, interpretation of the world is adjusted and becomes nearer to the goals.

This observation is principally valuable in the context of postal sector in Southern Africa which is overwhelmed by multiple stakeholders with multiple interests including policy directions internationally (Universal Postal Union), continentally (Pan African Postal Union), regionally (Southern African Postal Operators Association as implementing Agency of Southern Africa Development Community) and lastly nationally where individual postal operators operate. In this research the enablers and impediments that play in the adoption and diffusion of technology are identified including feedback loops that associate the several factors involved in the adoption and diffusion of technology process.

\section{Methodology}

In [70], the authors advances that research design can be classified in three categories which are (a) Exploratory research studies; (b) Descriptive and diagnostic research studies, and (c) Hypothesis-testing research studies. This study adopted the qualitative research design approach which is exploratory in nature.

In [71], the authors suggest that the idea behind qualitative research is to tenaciously hand-pick partakers or locations (or records or graphic materials) that enables the researchers to comprehend the conundrum (problem) and the research question. This fundamental feature of qualitative research design resulted in the in collection of specific secondary data that provides insight to the researcher to comprehend the phenomenon under study.
In [72], the author argues there are diverse forms of review methodologies; systematic, semi-systematic and integrative approaches and argues that each approach is appropriate depending on the purpose of analysis. This study adopted an integrative approach to literature reviews. An integrative approach is characterized by tenets which are articulated in Table 6 .

Table 6: Tenets of an integrative approach to literature reviews

\begin{tabular}{|l|l|}
\hline Tenet & Integrative Approach \\
\hline Typical rationale & Critique and integrate \\
\hline Research questions & Narrow or broad \\
\hline $\begin{array}{l}\text { Exploration } \\
\text { approach }\end{array}$ & Usually not methodical \\
\hline Sample attributes & Peer reviewed articles \\
\hline Evaluation & Qualitative \\
\hline $\begin{array}{l}\text { Examples } \\
\text { contribution }\end{array}$ & $\begin{array}{l}\text { Classification (Theoretical models or } \\
\text { frameworks) }\end{array}$ \\
\hline
\end{tabular}

The data was collected from archival data from literature and industry reports, this data focused on a variety of drivers and barriers common in adoption of technology in organizations as well as characteristics of factors that drive or impede technology adoption in organizations and as well as in the postal sector.

This exploratory, qualitative research design using integrative approach was aimed at answering at great length the first research question which is, "Can a generic framework for technology and digital transformation adoption be developed for Posts in Southern Africa?

In [71], the author avows that "The data collection steps include setting the boundaries for the study, collecting information through unstructured or semi structured observations and interviews, documents, and visual materials, as well as establishing the protocol for recording information". In [71], the author further argues that the objective of qualitative research is to tenaciously choose members or sites (or documents or visual material) that will assist the investigator to fully grasp the challenge and the research question. The study purposefully selected relevant literature from Universal Postal Union, the different postal operators, specific literature that deals with technology adoption, ICT adoption and digital transformation with the view of comprehending the problem and the associated research question.

\section{Discussion and findings}

The literature review accentuates the significance of not only dealing with barriers and drivers to adoption of technology and Industry 4.0 technologies but highlights the fact that these barriers and drivers are not linear but intermingles with each other in a dynamic setting. Literature divulges that adoption and technology diffusion processes are very complex and entails multiple interdependent drivers and barriers which are very dynamic involving numerous feedback processes that demonstrate nonlinearity characteristics.

Literature details the postal sector landscape, and reflects on the digital panorama globally, continentally and in the region 
(Southern Africa) and points to serious challenges faced by developing and less developed countries from a digital ecosystem point of view. These challenges are reflected in several barriers that need to be overcome and drivers that needs to be leveraged on in a dynamic setting.

Literature points to vast variances in digital adoption readiness between developed countries and developing countries, with specific reference to Southern Africa as depicted in Table 4 and Table 5 respectively and graphically depicted Figure 18 and Figure 19 , respectively.

\section{Digital Readiness of Posts}

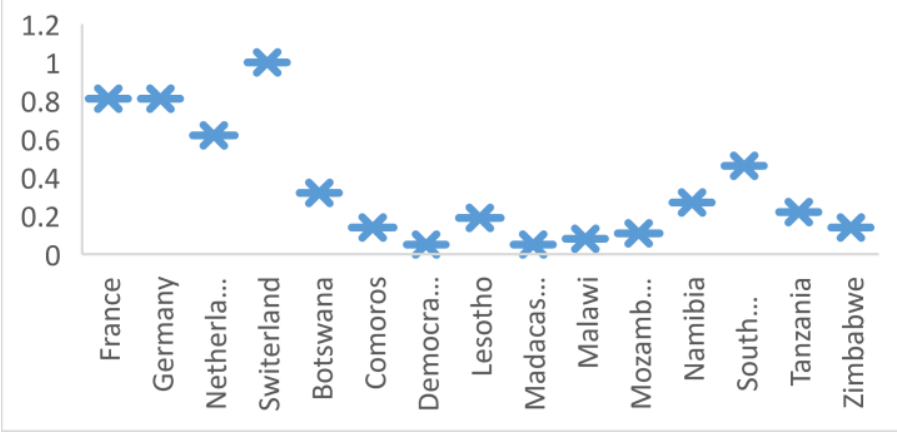

Figure 18: Digital readiness score of Posts

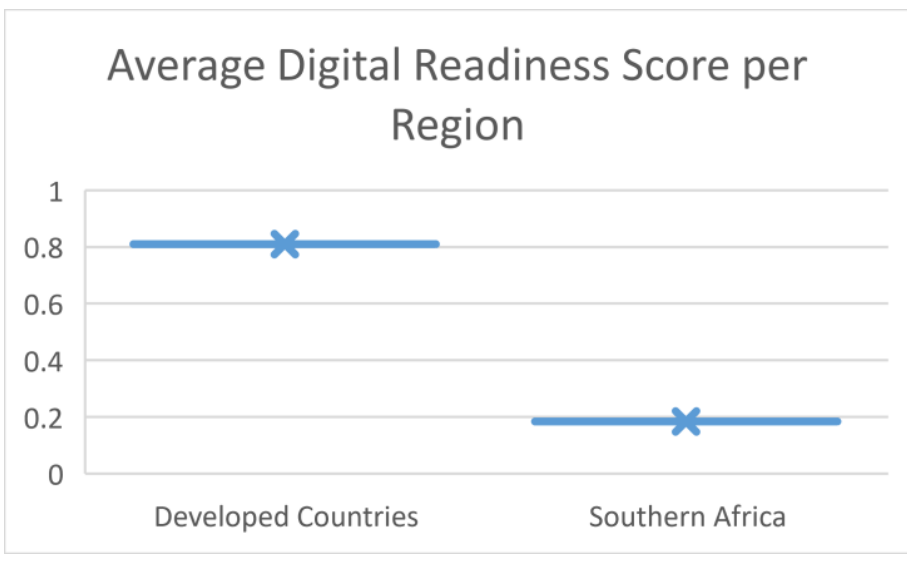

Figure 19: Average Digital readiness score per Region

The digital readiness score illustrates that Switzerland scores $100 \%$ and this is further supported by the performance of Switzerland on the Integrated Index on Postal Development in which it scores $100 \%$. Switzerland is followed by both Germany and France scoring $81 \%$ and The Netherlands scoring $62 \%$. The average of the four leading countries stands at $81 \%$.

Southern Africa ranges from maximum of $46 \%$ which represent the performance of South Africa to a minimum of 5\%, the variation within Southern Africa cumulatively results in an average of $18 \%$. The performance of Southern Africa should be seen in the context of a plethora of challenges facing the continent and the Southern Africa in the context of this study. These challenges require a concerted effort by Posts and respective national governments and regional bodies to address the legacy of colonialism but also the problems that occurred post-independence that continue to halt prospects of development.
Literature also points to Technology Acceptance Models TAM, TAM2, TRA, UTAUT, TOE, BOE, and ADOPT are among the most popular which highlight factors related to system users; however, there is a literature knowledge gap in these models handling other stakeholders who are directly or indirectly affected by the adoption process and the interaction of drivers and barriers in a dynamic setting. These technology acceptance models lack the important aspect of feedback systems which are at the core of systems thinking approach.

TRA, TAM, TAM2, and UTAUT are significant pioneers in the technology adoption space by elucidating the aspects that perform a prominent role in the process of technology adoption. The evolution from TRA to UTAUT is exemplified in Figure 20.

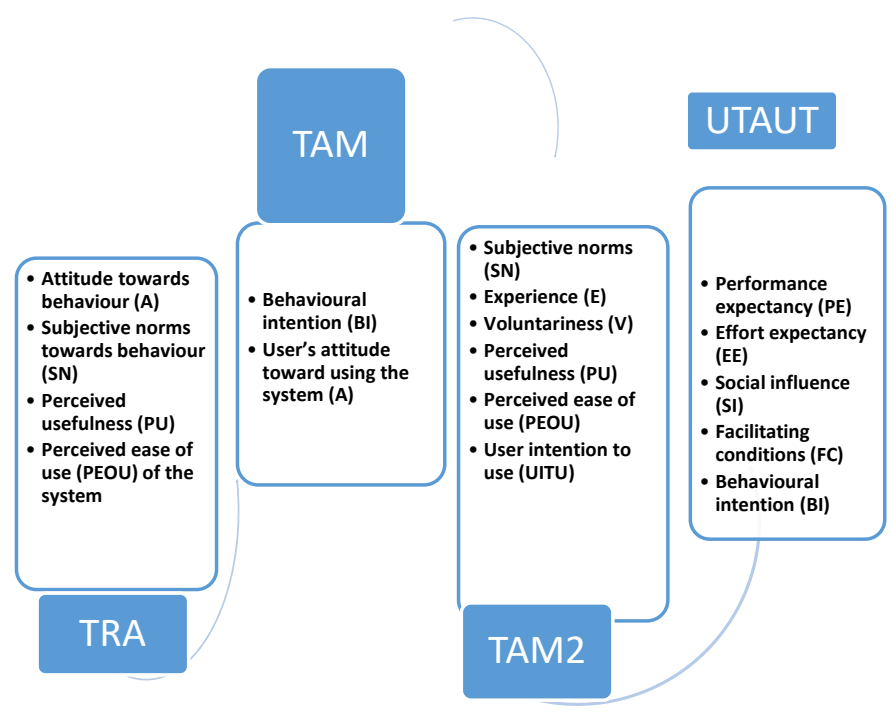

Figure 20: Evolution of technology adoption models

The factors elucidated in Figure 20 directly determine the user adoptability potential of technology, however they are applicable to individuals rather than organizations. The BOE and TOE attempts to address the limitations of TRA, TAM, TAM2 and UTAUT which are only applicable to individual's adoption of technology through articulation of constructs that are applicable to organization-wide adoption of technology. The constructs of BOE (Perceived Benefits, Organization Readiness and External Pressures) are depicted in Figure 21 and TOE constructs (Technology, Organization and External Environment) are depicted in Figure 22.

These factors associated with both TOE and BOE are an attempt to integrate organization-wide factors and external factors that are at play in the context of organization-wide adoption of technology adoption as opposed to the traditional technology adoption models in the form of TRA, TAM, TAM2 and UTAUT which are relevant to individual adoption of technology or new innovation. While TOE and BOE attempts to integrate factors associated with organization-wide adoption of technology and new innovation, they both lacked "causality" which is at play in a dynamic setting resulting in new emergence of patterns and mental models due to interacting factors that inhibit or enable adoption 
and diffusion of technology in a dynamic setting which result in even greater complexity. BOE and TOE are therefore not sufficient to explain nor explore the complex nature of interacting factors in the dynamic setting of the postal sector in Southern Africa.

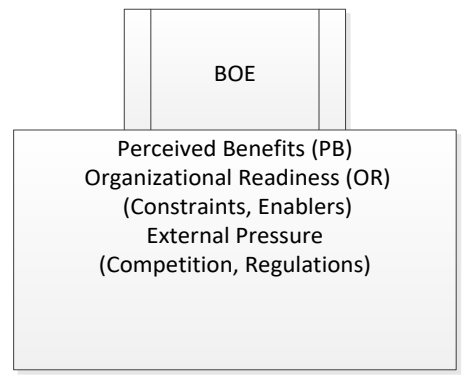

Figure 21: Constructs of the BOE model

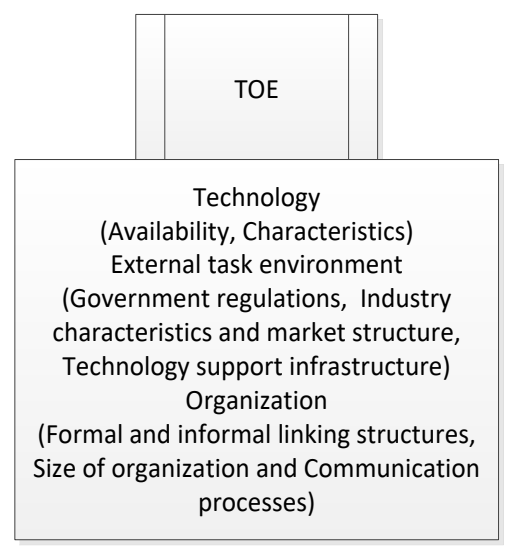

Figure 22: Constructs of the TOE model

The purpose of this research is to explore how best to close the limitations of the "linear" technology adoption models through the application of a holistic or systems thinking approach to identify systemic issues in technology adoption within Southern African context by considering the complete stakeholder system a "system of stakeholders" with their corresponding interests giving rise to various dynamic settings that could impede or enable technology adoption and digital transformation in the postal sector in Southern Africa.

The System Thinking approach which inherently integrates feedback systems is suitable for complex phenomenon like adoption of technology and digital transformation in the postal sector which is underpinned by multiple stakeholders with often opposing interests. A systems approach in comparison to traditional "linear" technology adoption models (TRA, TAM, TAM 2, UTUAT, TOE, BOE and ADOPT) was found to be the most appropriate and suitable for managing the interaction of barriers and drivers that are at play in a dynamic setting in the context of the postal sector in Southern Africa.

The literature suggests that Industry 4.0 is centred on digital transformation of business models. At its core is digitalization and integration of vertical and horizontal value chains, digitalization of offerings (products and services) and digitalization of business models and customer access. Of which, data and data analytics are core competencies interacting with digital technologies such as wearables and augmented reality, IoT platforms, mobile devices, big data and advanced algorithms, location detection technologies, $3 \mathrm{D}$ printing and other related Industry 4.0 technologies.

The critical review of literature explicates that the foundation to digital transformation is a systematic approach that is directed from a digital vision envisaged by the organization, the model proposed in [52] where the authors argues that the transformation requires organizations to move from level 1 (Initiate), to level 2 (Competent) to level 3 (Purposeful) and finally to level 4 (Transformative). The levels start from chaotic and no ambition or culture for innovation (level 1) to structured, systematic and innovative (level 4).

In [54], the authors articulates the three-stage model of envisioning of Industry 4.0, enablement of Industry 4.0 and lastly enacting of Industry 4.0. The three-staged model proposes 5 levels of digital maturity ranging from the lowest level (Level 1) in which the Industry 4.0 vision is not defined to the highest level (Level 5) in which there is complete business model transformation. The insights and inferences that could be drawn that without a solid vision and an underpinning strategy which acts as a roadmap for organizations with demonstrable projects; the adoption of technological innovation and digital transformation is set to fail.

In [53], the authors proposes the five dimensions that underpins digital transformation journey and are (a) Customers, (b) Strategy, (c) Technology, (d) Operations and (e) Organization and culture are key towards digital transformation journey that is structured to ensure success.

The proposed technology and digital adoption conceptual framework as presented in Figure 23 espouses the insights drawn from the critical review of selected literature.

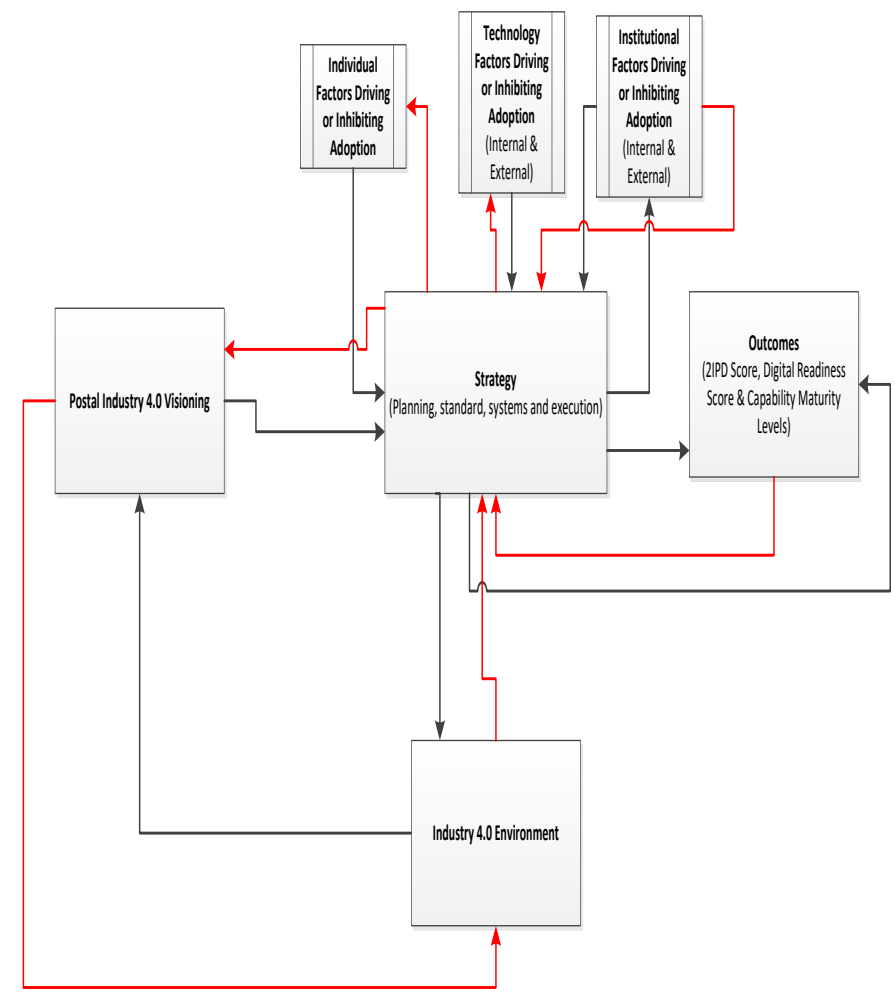

Figure 23: Proposed postal industry 4.0 adoption framework 
The framework proposed commences with the visioning dimension which is a key critical success factor in adoption of digital technology and digital transformation. It sets the agenda for digital transformation of the Postal Sector in Southern Africa and without a vision for postal industry 4.0, the digital transformation process is bound to fail. The visioning dimension is supported by the strategy which integrates aspects of planning, systems relating to Industry 4.0, standards relating to Industry 4.0 and execution of strategic imperatives into concrete programmes and projects.

This dimension of strategy interacts with factors that inhibit or enable digital technology adoption and technology adoption broadly. These factors that either inhibit or enable adoption of digital technology and technology broadly are technological, institutional, and individual focused. These factors should be factored in during the strategy development phase and take cognizance of Industry 4.0 standards and systems prevailing. The strategy dimension also feedforwards to the Industry 4.0 environment which is meant to facilitate the core capabilities of Industry 4.0 which are data and analytics, aimed at supporting the core fundamental goal of Industry 4.0 which are: Digitalization and integration of horizontal \& vertical value chains, digitalization of products and service offerings includes the expansion of existing products; and lastly, digital business models and customer access.

The execution of the vision for postal industry 4.0 through execution of strategy is envisaged to improve outcomes in the form of an improved 2IPD score, improved digital readiness score and improved capability maturity for the postal industry in Southern Africa.

The technology and digital objectives are underpinned by 5 strategic objectives which are:

1. Adoption of Industry 4.0 in the postal sector (Postal Industry 4.0)

2. Digital transformation readiness

3. Improvement of digital readiness by Posts in Southern Africa through capability maturity modelling

4. Adoption and diffusion of technological innovation

5. Improvement on the 2IPD score

A system approach is represented by feedback systems that are represented as red lines and arrows. Feedback systems are the foundation of the proposed approach as they mimic a dynamic setting due to interaction of a plethora of factors and outcomes.

The critical findings of this study can be summarized as:

(a) The traditional technology adoption models are particularly relevant to individual level rather than organizational level

(b) The TOE (Technology, Organization and Environment) model is the first attempt to incorporate organizational-wide adoptability of technology. However, the approach is linear in nature rather than systemic as feedback systems which are at play in a dynamic setting are lacking.

(c) That there is a big variation in performance on the 2IPD and on digital readiness index between the first-tier countries and Southern Africa. This variation is driven by digital culture which is lower in Southern Africa as compared to top-tier countries (Switzerland, The Netherlands, Germany, France, and Japan).

(d) Visioning and strategy drive digital transformation, without a robust visioning and strategy (including digital culture), the outcomes in terms of performance on both 2IDP and digital readiness index will always be below expectation.

(e) A linear approach to digital transformation and technology adoption fails to capture the complexities associated with interaction of factors in a dynamic setting resulting with even greater complexity.

\section{Conclusions}

Universally, the postal sector is faced with a plethora of challenges regarding the ever-changing world that is driven by volatility, uncertainty, complexity, and ambiguity (VUCA). This research presented the postal landscape with specific reference to performance of Southern Africa as a Region against the top 5 postal operators on the Universal Postal Union's Integrated Index on Postal Development.

The limitations of the technology adoption models were presented and discussed in context of their "linearity" or rather, a reductionist approaches to technology adoption as opposed to a systems approach which was presented and discussed in detail together with its respective tenets of which feedback systems are fundamental cornerstone to a system approach where the paradigm is "causality" rather than "linearity".

The conceptual framework that incorporates a system approach was presented and discussed in detail, with its respective tenets derived through insights obtained from critical review of literature. In [1], the authors presented a theoretical model at IEEM 2019. The proposed conceptual model as depicted in Figure 23; it is an enrichment of the earlier theoretical framework presented. It is a build-up towards the final goal of developing a dynamic model towards technology and digital adoption in the postal sector in Southern Africa. The conceptual framework answers the research question which was the guiding ingot to the critical literature review.

The research gap identified in this study is the failure of traditional technology adoption models in driving digital transformation agenda. The linearity fails to capture adoption dynamics in a dynamic setting as opposed to the proposed adoption model with build-in feedback loops to better understand interaction of drivers and barriers in an evolving dynamic setting as in the real world.

Future research will be the development of a conceptual framework using system dynamics where the drivers and barriers identified in the research are modelled in a dynamic setting to understand patterns that emerge from their interaction. The developed system dynamic conceptual model will be rigorously tested by selected participating Posts to further refine the model until it closely represents reality. The validated model could be used by Posts to model different drivers and barriers with a view of mitigating against barriers that would enable Posts in Southern Africa to fully adopt a digital transformation journey in order to be sustainable now and in the future. 


\section{Conflict of Interest}

The authors declare no conflict of interest.

\section{References}

[1] K. Mokgohloa, M.G. Kanakana-Katumba, R.W. Maladzhi, J.A. Trimble, "Postal Development: Literature Review into Adoption Models," IEEE International Conference on Industrial Engineering and Engineering Management, 2, 764-768, 2019, doi:10.1109/IEEM44572.2019.8978531.

[2] UPU, Annual Strategic Review 2017, Bern, 2017.

[3] UPU, "Postal Development Report 2018 - Benchmarking a critical infrastructure for sustainable development," (April), 1-32, 2018.

[4] C. Barman, A., Potsangbam, "Shifts of Strategic Paradigms in the VUCA World- Does 'outside the box thinking' a meaningful cliché for the business world?," (July 2018), 2017.

[5] B. Cousins, "Design thinking: Organizational learning in VUCA environments," Academy of Strategic Management Journal, 17(2), 1-18, 2018.

[6] N. Balasubramanian, "Innovative Operation Strategies in VUCA world," 2319-7668, 2018.

[7] P. Hallo, Leonie; Nguyen, Tiep; Gorod, Alex; Tran, "Effectiveness of Leadership Decision-Making in Complex Systems," Systems, 8(5), 2-21, 2020.

[8] SADC, SADC postal strategy 2017-2020, 2017.

[9] SAPOA, SAPOA Strategy Implementation Plan 2017 - 2020 Version 4, SAPOA, Maseru, 2016.

[10] UPU, postal Development Report 2018, Universal Postal Union, Bern, 2018.

[11] Universal Postal Union, The digital economy and digital postal activities - a global panorama, Universal Postal Union, Bern, 2019.

[12] UPU, Postal Development Report 2019, Berne, 2019.

[13] T. Santos, Beatrice; Chaura-Santos, F; Lima, "Industry 4.0: an overview," Research G, (July), 2018.

[14] H. Lasi, P. Fettke, H.G. Kemper, T. Feld, M. Hoffmann, "Industry 4.0," Business and Information Systems Engineering, 6(4), 239-242, 2014, doi:10.1007/s12599-014-0334-4.

[15] Universal Postal Union, The digital economy and digital postal activities - a global panorama, 2019.

[16] G. Reinhard, V. Jesper, S. Stefan, Industry 4.0: Building the digital enterprise, 2016, doi:10.1080/01969722.2015.1007734.

[17] A. Rojko, "Industry 4.0 Concept: Background and Overview," International Journal of Interactive Mobile Technologies (IJIM), 11(5), 2017, doi:10.3991/ijim.v11i5.7072.

[18] Deloitte, Industry 4.0 Challenges and solutions for the digital transformation and use of exponential technologies, 2015, doi:10.1057/9780230514027_2.

[19] L.D. Galindo, The Challenges of Logistics 4.0 for the Supply Chain Management and the Information Technology, 2016, doi:10.1038/npp.2015.289.

[20] B. Hermann, Mario; Pentek, Tobias; Otto, Ultrafast synthesis of bifunctional $\mathrm{Er} 3+/ \mathrm{Yb} 3+$-codoped $\mathrm{NaBiF} 4$ upconverting nanoparticles for nanothermometer and optical heater, Gallen, 2015, doi:10.1016/j.jcis.2017.12.027.

[21] J. Macaulay, L. Buckalew, G. Chung, Internet of Things in Logistics, 2015.

[22] F. Jindal, R. Jamar, P. Churi, "Future and Challenges of Internet of Things," International Journal of Computer Science and Information Technology, 10(2), 13-25, 2018, doi:10.5121/ijcsit.2018.10202.

[23] USPS, The Internet of Postal Things Report Number RARC-WP-15-013, Virginia, 2015.

[24] M.A. Rahman, A.T. Asyhari, "The emergence of internet of things (Iot): Connecting anything, anywhere," Computers, 8(2), 8-11, 2019, doi:10.3390/computers8020040.

[25] UPU, Postal development report, Berne, 2018.

[26] G. Kuehne, R. Llewellyn, D.J. Pannell, R. Wilkinson, P. Dolling, J. Ouzman, M. Ewing, "Predicting farmer uptake of new agricultural practices: A tool for research, extension and policy," Agricultural Systems, 156(August 2016), 115-125, 2017, doi:10.1016/j.agsy.2017.06.007.

[27] E.M. Rogers, Diffusions of Innovations, 1995.

[28] E.M. Rogers, M. Everett, Diffusion of Innovatons, 1983.

[29] R. Sharma, R. Mishra, "A Review of Evolution of Theories and Models of Technology Adoption," Indore Management Journal (IMJ), 6(2), 17-29, 2014.

[30] C. Dube, V. Gumbo, "Diffusion of Innovation and the Technology Adoption Curve: Where Are We? The Zimbabwean Experience," Business and Management Studies, 3(3), 34, 2017, doi:10.11114/bms.v3i3.2500.
[31] A. Kogabayev, Timur; Maziliauskas, "The definition and classification of innovation," Holistica, 8(1), 59-72, 2017, doi:10.1515/hjbpa-2017-0005.

[32] S. Xaba, Evaluation of South African Post Office SOC Ltd Innovation Efficacy, University of Pretoria, 2012.

[33] P.F. Drucker, Innovation and Entrepreneurship: Practice and Principles, HarperCollins Publishers, London, 1985.

[34] M. De Jong, N. Marston, E. Roth, "The eight essentials of innovation," McKinsey Quarterly, (2), 36-47, 2015.

[35] J.P. Wentzel, K.S. Diatha, V.S.S. Yadavalli, "An application of the extended Technology Acceptance Model in understanding technology-enabled financial service adoption in South Africa," Development Southern Africa, 30(4-5), 659-673, 2013, doi:10.1080/0376835X.2013.830963.

[36] D. Mugo, K. Njagi, B. Chemwei, J. Motanya, "The Technology Acceptance Model (TAM) and its Application to the Utilization of Mobile Learning Technologies," British Journal of Mathematics \& Computer Science, 20(4), 1-8, 2017, doi:10.9734/BJMCS/2017/29015.

[37] J.P. Wentzel, Modelling Financial Services Adoption Through an Intermediary in South Africa: TAM and SEM Approach, Pretoria, 2012.

[38] Q. Ma, L. Liu, "The Technology Acceptance Model," Advanced Topics in End User Computing, 4, (January), 2011, doi:10.4018/9781591404743.ch006.ch000.

[39] M. Chuttur, "Technology Acceptance, Information System Deployment, TAM, Information System Theory," Sprouts, 9(2009), 2009.

[40] P.. Davids, F.D; Bagozzi, R.P; Warshaw, "User Acceptance of Computer Technology: A Comparison of Two Theoretical Models," Management Science, 35(8), 982-1003, 1989.

[41] P. Lai, "the Literature Review of Technology Adoption Models and Theories for the Novelty Technology," Journal of Information Systems and Technology Management, 14(1), 21-38, 2017, doi:10.4301/s180717752017000100002.

[42] V. Venkatesh, F.D. Davis, "Theoretical extension of the Technology Acceptance Model: Four longitudinal field studies," Management Science, 46(2), 186-204, 2000, doi:10.1287/mnsc.46.2.186.11926.

[43] F. Venkatesh, Viswanath; Morris, Michael; Davis, Gordon; Davids, "User Acceptace of Information Technology: Towards a Unified View," MIS Quarterly, 27(3), 95-98, 2003.

[44] C.M. Chao, "Factors determining the behavioral intention to use mobile learning: An application and extension of the UTAUT model," Frontiers in Psychology, 10(JULY), 1-14, 2019, doi:10.3389/fpsyg.2019.01652.

[45] Y.K. Dwivedi, N.P. Rana, A. Jeyaraj, M. Clement, M.D. Williams, "Reexamining the Unified Theory of Acceptance and Use of Technology (UTAUT): Towards a Revised Theoretical Model," Information Systems Frontiers, 21(3), 719-734, 2019, doi:10.1007/s10796-017-9774-y.

[46] H. Gangwar, H. Date, R. Ramaswamy, "Understanding determinants of cloud computing adoption using an integrated TAM-TOE model," Journal of Enterprise Information Management, 28(1), 107-130, 2015, doi:10.1108/JEIM-08-2013-0065.

[47] T. Oliveira, M. Martins, "Literature Review of Information Technology Adoption Models at Firm Level.," Electronic Journal of Information ..., 2011.

[48] A. Dasgupta, S. Wendler, “AI Adoption Strategies," (9), 1-13, 2019.

[49] G. Kuehne, C. Nicholson, M. Robertson, R. Llewellyn, C. McDonald, "Engaging project proponents in R\&D evaluation using bio-economic and socio-economic tools," Agricultural Systems, 108, 94-103, 2012, doi:10.1016/j.agsy.2012.01.009.

[50] K. Crowston, J. Qin, "A capability maturity model for scientific data management: Evidence from the literature," Proceedings of the ASIST Annual Meeting, 48(February), 2011, doi:10.1002/meet.2011.14504801036.

[51] M.C. Paulk, B. Curtis, M.B. Chrissis, C. V Weber, "for Software, Version 1. 1 Software Engineering Institute," Office, 40(February), 1-26, 1993.

[52] M. Shahiduzzaman, M. Kowalkiewicz, R. Barrett, M. McNaughto, Digital Business: Towards a Value Centric Maturity Model, 2017.

[53] Deloitte, Deloitte Digital Maturity Model, 2018.

[54] J. Ganzarain, N. Errasti, "Three stage maturity model in SME's towards industry 4.0," Journal of Industrial Engineering and Management, 9(5), 2016, doi:10.3926/jiem.2073.

[55] M. Rafferty, "Reductionism, Holism and System Dynamics," Proceedings of the 2007 International Conference of the System Dynamics Society, 2007.

[56] M. Dafermos, "Encyclopedia of Critical Psychology," Encyclopedia of Critical Psychology, (April), 2014, doi:10.1007/978-1-4614-5583-7.

[57] P. Mella, "Systems Thinking: The art of understanding the dynamics of systems," Journal of Learning, 15(January), 2015.

[58] D.H. Meadows, Thinking in Syatems, Earthscan, London, 2009.

[59] H. Sillitto, P. Godfrey, "Defining " System " : A Comprehensive Approach," in 27th Annual INCOSE International Symposium, INCOSE, Adelaide, 
2017.

[60] M. Jamshidi, “Systems thinking," IEEE Transactions on Neural Systems and Rehabilitation Engineering, 16(4), 1-4, 2008, doi:10.1109/TNSRE.2008.929253.

[61] J.D. Sterman, Business Dynamics: Systems thinking and modeling for a complex world, McGraw-Hill, London, 2000, doi:10.4324/97813511527237.

[62] J.D.W. Morecroft, Strategic Modelling and Business Dynamics, 2015, doi:10.1002/9781119176831.

[63] E.. Schumacher, Introduction to Systems Thinking Principles and Analytical Tools, 2019.

[64] S. Peter, The Fifth Discipline:The art and practice of learning organisation, Doubleday, New York, 1990.

[65] J.D. Sterman, L.B. Sweeney, "Bathtub dynamics: initial results of a systems thinking inventory," System Dynamics Review, 16(4), 249-286, 2000.

[66] R.D. Arnold, J.P. Wade, "A definition of systems thinking: A systems approach," Procedia Computer Science, 44(C), 669-678, 2015, doi:10.1016/j.procs.2015.03.050.

[67] J.D. Sterman, "System dynamics modeling: Tools for learning in a complex world," IEEE Engineering Management Review, 30(1), 42-52, 2002, doi:10.1109/EMR.2002.1022404.

[68] M. Reinker, E. Gralla, "A System Dynamics Model of the Adoption of Improved Agricultural Inputs in Uganda, with Insights for Systems Approaches to Development," Systems, 6(3), 31, 2018, doi:10.3390/systems6030031.

[69] D.K. Fisher, J. Norvell, S. Sonka, M.J. Nelson, "Understanding technology adoption through system dynamics modeling: Implications for agribusiness management," International Food and Agribusiness Management Review, 3(3), 281-296, 2000, doi:10.1016/s1096-7508(01)00048-9.

[70] P.D. Leedy, J.E. Ormrod, John W. Creswell, S. Greener, W. Askarzai, B. Unhelkar, D.J. Currie, C. Smith, P. Jagals, D. Williams, H. Snyder, H.K. Mohajan, H.K. Mohajan, J.M. Brayer, O. Skovsmose, M. Borba, M.A. Ragab, A. Arisha, S. Rajasekar, P. Philominathan, S. Macdonald, N. Headlam, U. Sekaran, C. Kothari, Research Design, Eleventh E, SAGE, Essex, 2004, doi:10.1186/s12889-018-5318-8.

[71] J.W. Creswell, Research Design, Fourth Edi, SAGE, London, 2014.

[72] H. Snyder, "Literature review as a research methodology: An overview and guidelines," Journal of Business Research, 104(August), 333-339, 2019, doi:10.1016/j.jbusres.2019.07.039. 